\title{
Kommunikation kann man lernen!
}

\section{Liebe Leserinnen und Leser,}

die Aussage, dass Kommunikation für Controller wichtig ist, mag auf den ersten Blick banal wirken. Klar: Controller sollen nicht nur im Kämmerchen sitzen und ihre Erbsen zählen. Vielmehr müssen sie ihre Zahlen und Analysen verkaufen und in zahlreichen Budgetierungsrunden ein Gefühl dafür entwickeln, was geht und was nicht. Zudem müssen sie im Bedarfsfall ihre Manager davon überzeugen, dass deren (bisherigen) Lieblingsideen nicht tragfähig sind und dass grundlegende Veränderungen im Unternehmen auch in ihrem Bereich Sinn machen. Kommunikation kommt in all diesen Aspekten eine zentrale Rolle zu, entsprechende Fähigkeiten des Controllers werden regelmäßig gefordert und fehlen in kaum einem Anforderungsprofil.

Allein bei der Umsetzung der Postulate hapert es häufig. Kommunizieren - so ist oft zu hören - kann man eben (oder nicht). Außer der einen oder anderen Fortbildungsmaßnahme, die eine bessere Rhetorik im Vortrag oder wirkungsvollere Schaubilder bewirken soll, geschieht in aller Regel auch wenig, um Controller systematisch beim Aufbau entsprechender Fähigkeiten zu unterstützen. Auch in der universitären Ausbildung liegt der Schwerpunkt traditionell überall, nur nicht in der Stärkung der kommunikativen Fähigkeiten der Studierenden. Ein Blick über den Atlantik zeigt, dass es auch anders geht: Amerikanische Business Schools bieten regelmäBig Kurse an, die Verhandlungs- und Verkaufsstrategien, strukturierte Problemlösung und ebenso strukturierte Kommunikation von Ergebnissen zum Inhalt haben. Dabei geht es eben nicht nur um Rhetorik und schöne Schaubilder, sondern um eine fundierte Vermittlung rationaler Strategien und psychologischer Mechanismen, denen Verhandlungs-, Verkaufsund Problemlösungsprozesse zugrunde liegen.

An der WHU - Otto Beisheim School of Management haben wir vor fünf Jahren damit angefangen, entsprechende Kurse systematisch in die Ausbildung unserer Studierenden einzubauen. Das Ergebnis ist ermutigend: Die interaktiv angelegten Kurse sind zwar fordernd, aber überaus beliebt. Denn die Studierenden merken intuitiv, dass sie hier um- und einsetzbare Fähigkeiten erlernen, die in der Unternehmens-

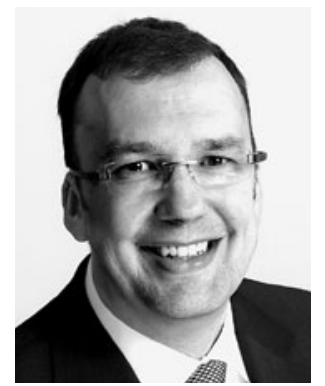

Utz Schäffer

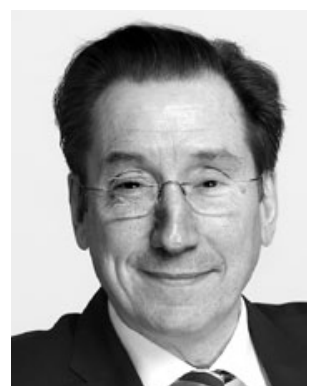

Jürgen Weber praxis den entscheidenden Unterschied machen können - in der Zukunft wohl noch mehr als heute.

In dem Maße, wie routinebasierte Backoffice-Tätigkeiten zunehmend standardisiert, automatisiert oder - in Großunternehmen - an kostengünstigen Standorten zentralisiert werden, wird der Anteil von kommunikationsintensiven Tätigkeiten im Controlling nochmals deutlich ansteigen. Nimmt man das Konzept des Controllers als Business Partner ernst, merkt man schnell: Es setzt ausgeprägte kommunikative Fähigkeiten mindestens genauso voraus wie analytisches Denken. Mit dem vorliegenden Heft wollen wir daher Ihre Aufmerksamkeit auf das vielschichtige Phänomen der Kommunikation lenken und nicht nur den Dialog zwischen Managern und Controllern, sondern auch die Kommunikation innerhalb der Finanzfunktion, die Rolle, die dem Controlling an der Schnittstelle zu Investor Relations und Kapitalmarktfunktion zukommt, und nicht zuletzt die kommunikativen Herausforderungen großer Transformationsprojekte beleuchten.

Viel Spaß bei der Lektüre wünschen Ihnen
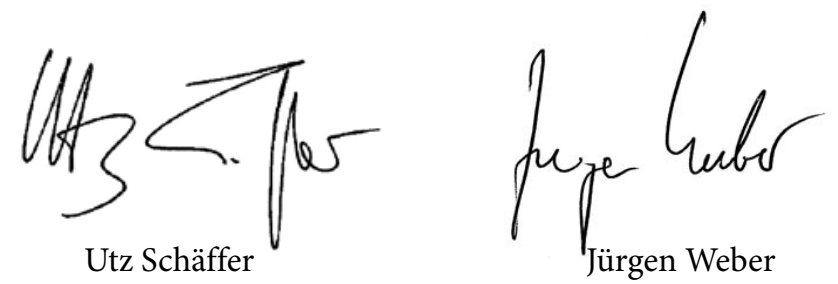